\title{
Psychotic relapse and associated factors among patients attending health services in Southwest Ethiopia: a cross-sectional study
}

Mahlet Fikreyesus ${ }^{1}$, Matiwos Soboka ${ }^{2}$ and Garumma Tolu Feyissa ${ }^{3,4^{*}}$

\begin{abstract}
Background: Psychotic relapse leads to repeated hospitalization and negatively affects the clinical prognosis of the patients. Information on prevalence of relapse among patients with psychotic disorders in Ethiopian setting is scarce. This study aimed to assess the prevalence of relapse among patients with psychotic disorders attending services in Jimma University Specialized Hospital (JUSH).

Methods: Data were collected using interviewer administered questionnaire. We used medication adherence rating scale (MARS) to assess compliance to medication and abnormal involuntary movement scale (AIMS) to detect medication side effects. Logistic regression analysis was used to identify independent predictors of psychotic relapse. All variables with $P$-value $<0.25$ in the bivariate analyses were entered into multivariate logistic regression and variables with $P$-value $<0.05$ in the final model were declared to be significantly associated with the outcome variable.

Results: The prevalence of relapse among patients with psychotic disorder was $24.6 \%(n=95)$. Of this, 25.4 and $22.4 \%$ were males and females respectively. The odds of developing psychotic relapse among patients living with family was $72 \%$ lower than that of patients living alone $(\mathrm{aOR}=0.28,95 \% \mathrm{Cl}=0.08,0.93)$. The odds of developing psychotic relapse among patients compliant to medication was $69 \%$ lower than that of patients who were not compliant to medications ( $\mathrm{aOR}=0.31,95 \% \mathrm{Cl}=0.12,0.80$ ). The odds of developing psychotic relapse among patients having high score on social support score was $48 \%$ lower than that of patients who were compliant to medications ( $\mathrm{aOR}=0.52$, $95 \% \mathrm{Cl}=0.28,0.95$ ). The odds of developing psychotic relapse among patients reporting to have sought religious support was $45 \%$ lower than that of patients who have not sought religious support $(a \mathrm{OR}=0.55,95 \% \mathrm{Cl}=0.31,0.96)$. On the other hand, the odds of developing psychotic relapse among participants who have experienced medication side effects was 1.83 times higher when compared to those who have never experienced medication side effects $(\mathrm{aOR}=1.83,95 \% \mathrm{Cl}=1.01,3.31)$.

Conclusions: The high prevalence of relapse among patients with psychotic disorder needs special attention. Clinicians need to pay attention to medication side effects the patient faces. Intervening noncompliance to medication and appropriately managing medication side effects may help in preventing psychotic relapse that may result because of non-compliance. The provision of counseling, psycho education, psycho social support may help patients in improving compliance to medication and reducing psychotic relapse. Developing and strengthening community based rehabilitation services should be emphasized as part of mental healthcare services.
\end{abstract}

Keywords: Relapse, Psychotic disorders, Substance use, Medication side effect, Medication compliance, Ethiopia

\footnotetext{
* Correspondence: garumma.feyissa@adelaide.edu.au

${ }^{3}$ Department of Health Education and Behavioral Science, Jimma University, Jimma, Ethiopia

${ }^{4}$ The Joanna Briggs Institute, University of Adelaide, Adelaide, Australia

Full list of author information is available at the end of the article
} 


\section{Background}

Mental illness is among the prevalent non-communicable diseases worldwide [1]. Mental health negatively affects both the patient and the family members financially and socially [2]. The stigma attached to schizophrenia creates a vicious cycle of discrimination leading to social isolation, unemployment, drug abuse, long lasting institutionalization or even homelessness, which further decreases the chances of recovery. Families of patients carry the burden of caring for patients through restricted social activities and economic problems [3]. Relapse costs a lot for patients and their families and imposes a financial burden on hospital and community services [4]. Costs for relapse cases were four times higher than that of non-relapse cases [5]. Relapse cases are associated with hospital admissions. The cost of hospitalization contributes to one- to two- third of the cost for the care of schizophrenia [6]. Relapses may also lead the patients to stay on medication for a longer period of time [7]. Relapse was associated with medication side effects [8-11], substance use [12-15], long stay before initiating therapy [16-18] and comorbid medical or psychiatric illness [19-21].

A study conducted in rural Ethiopia showed that, families of patients diagnosed with schizophrenia had spent $\$ 16.52$ out-of-pocket and on average spent $3.12(\mathrm{SD}=4.54)$ days of work due to care giving in one month [22]. However, there is limited data on prevalence of relapse and associated factors among patients with psychotic disorders. Therefore, this research aimed at assessing the prevalence of, and risk factors for relapse among patients with psychotic disorders.

\section{Methods}

\section{Study setting}

This cross-sectional study was conducted in Jimma University specialized hospital (JUSH), which is located in southwestern part of Ethiopia $354 \mathrm{~km}$ far from Addis Ababa. Jimma University specialized hospital provides psychiatric services for inpatient and outpatient services [23]. The outpatient psychiatry clinic at JUSH was established in 1988. Data collection for this research was conducted in November, 2013.

\section{Sample size determination and sampling procedure}

The sample size for the study was determined by assuming relapse rate of $50 \%$ giving any particular out come to be with in $5 \%$ marginal error and $95 \%$ confidence interval of certainty (alpha $=0.05)$. Based on this assumption, the actual sample size calculated for this study was 386. All adult patients were invited to participate in the study consecutively.

\section{Data collection instrument}

Data were collected using a structured interviewer administered questionnaire on the following variables:

Relapse among patients with psychotic disorder A structured interviewer administered questionnaire containing a yes or no question was used to assess relapse. We assessed relapse based on the DSM IV-TR relapse definition criteria [24]. Patients were asked about the numbers of relapses they had. In addition, we reviewed their charts to identify the recorded numbers of relapses.

Factors associated with relapse

Socio demographic factors: The structured questionnaire contained questions on sociodemographic and socio-economic status of the patients (age, sex, marital status, and educational level, and ethnicity, frequency of attending a place of worship, occupation, income and living condition).

Medication related factors: We used medication adherence scale (MARS) to assess adherence to anti-psychotic medication [25]. Patients who responded 'no' for questions numbers 1-6 and 9-10 and 'yes' for question numbers 7-8 were considered as compliant. And those patients who responded 'yes' for question numbers 1-6 and 9-10 and 'no' for question numbers 7-8 were considered as noncompliant [26]. Also abnormal involuntary movement scale (AIMS) was used to assess medication side effects. The AIMS is considered as standard clinical practice for patients receiving long term neuroleptic drugs and it was applied by clinicians [27, 28]. Substance use disorders: We utilized CAGE (cudown, annoyed, guilty and eye opener) to screen alcohol use disorder. Two or more positive responses on CAGE are indicative of alcoholism [29]. We used Drug abuse screening test (DAST) to assess khat abuse [30]. Khat is a leaf, which is one among psychoactive substances and it is commonly used in East Africa including Ethiopia [31, 32] The interpretation of DAST is follows: a score of zero indicates absence of substance abuse, 1-2 indicate low level of substance abuse, 3-5 indicate moderate level of substance abuse, 6-8 indicate substantial level of substance abuse and 9-10 indicate severe level of substance abuse. Those participants having moderate level of substance abuse need referral to professionals [33-35]. Duration of untreated psychotic disorder and Comorbidity: The participants were asked to indicate the duration of time they stayed before they sought therapy at modern health services after the onset of the illness. In addition, we asked the places they went before they sought services at modern health institutions. 
Table 1 Socio-demographic characteristics of patients with psychotic disorders, Jimma University Specialized Hospital, Ethiopia, $2013(n=386)$

\begin{tabular}{|c|c|}
\hline Socio demographic characteristics & Number (percent \\
\hline \multicolumn{2}{|l|}{ Sex } \\
\hline Male & $279(72.3 \%)$ \\
\hline Female & $107(27.7 \%)$ \\
\hline \multicolumn{2}{|l|}{ Age } \\
\hline $18-24$ & 79 (20.5\%) \\
\hline $25-34$ & $186(46.2 \%)$ \\
\hline $35-44$ & $82(21.2 \%)$ \\
\hline $45-54$ & $28(7.3 \%)$ \\
\hline $55-68$ & $11(2.8 \%)$ \\
\hline \multicolumn{2}{|l|}{ Religion } \\
\hline Orthodox & $97(25.1 \%)$ \\
\hline Muslim & $234(60.4 \%)$ \\
\hline Protestant & $51(13.2 \%)$ \\
\hline Catholic & $1(0.3 \%)$ \\
\hline Other* & $3(0.8 \%)$ \\
\hline \multicolumn{2}{|l|}{ Frequency } \\
\hline Frequent & 170 (44 \%) \\
\hline Sometimes & $196(50.8 \%)$ \\
\hline Never & $20(5.2 \%)$ \\
\hline \multicolumn{2}{|l|}{ Ethnicity } \\
\hline Oromo & $239(61.9 \%)$ \\
\hline Amhara & $66(17.1 \%)$ \\
\hline Gurage & $19(4.9 \%)$ \\
\hline Kaffa & $26(6.7 \%)$ \\
\hline Dawro & $20(5.2 \%)$ \\
\hline Yem & $5(1.3 \%)$ \\
\hline Other** & $11(2.8 \%)$ \\
\hline \multicolumn{2}{|l|}{ Marital status } \\
\hline Single & $179(46.4 \%)$ \\
\hline Married & $188(48.7 \%)$ \\
\hline Divorced & $11(2.88 \%)$ \\
\hline Separated & $2(0.5 \%)$ \\
\hline Widowed & $6(1.6 \%)$ \\
\hline \multicolumn{2}{|l|}{ Educational } \\
\hline Illiterate & $50(13 \%)$ \\
\hline Primary & 176 (45.6\%) \\
\hline Secondary & 96 (24.9\%) \\
\hline Tertiary & $64(16.6 \%)$ \\
\hline \multicolumn{2}{|l|}{ Occupation } \\
\hline Unemployed & 112 (29 \%) \\
\hline gov't employee & 87 (22.5 \%) \\
\hline Merchant & 26 (6.7 \%) \\
\hline
\end{tabular}

Table 1 Socio-demographic characteristics of patients with psychotic disorders, Jimma University Specialized Hospital, Ethiopia, 2013 ( $n=386)$ (Continued)

\begin{tabular}{ll}
\hline Private & $29(7.5 \%)$ \\
Farmer & $97(25.1 \%)$ \\
Other*** & $35(9.1 \%)$ \\
Income & \\
$167-541$ & $96(24.9 \%)$ \\
$542-1000$ & $120(31.1 \%)$ \\
$1001-1888$ & $75(19.4 \%)$ \\
$1889-10000$ & $95(24.6 \%)$ \\
\hline
\end{tabular}

Other* includes Jehovah's witnesses

Other** includes Tigrae, Wolayita and Hadiya

Other*** includes wood workers, daily laborer, house wife and students

Social support: We measured social support using six items. Each question had two parts. The first part is about the number of individuals that participants listed as a source of support and the second one is their level of satisfaction [36].

\section{Data collection procedures}

The questionnaire was pretested on a sample equal to $5 \%$ of the total sample size that were not part of the main study. Data were collected by interviewing patients with diagnosis of psychotic disorders coming to JUSH psychiatry clinic for follow-up purposes. Three psychiatric nurses and two postgraduate students attending their studies in masters program in integrated community and clinical mental health (ICCM) collected the data. Two students attending masters program in ICCM and the principal investigator supervised the data collection. Before the data collection, a two-days training was given for the data collectors and suppervisors. The training included detailed information on how to collect data, how to score the different scales used in the study and how to perform AIMS. The supervisor monitored data quality and checked all questionnaires for completeness.

\section{Data analysis}

Data were checked for completeness, and were entered into Epi-Data version 3.1. After double entry verification, the data were exported to SPSS (statistical package for social science) version 20 for analyses.

The dependent variable (relapse) and independent variables (predictors) were entered into bivariate logistic regression in order to determine statitical association between dependent and independent variables. All variables associated with the dependent variable with $p$-value less than 0.25 in the bivariate analyses of the binary logistic regression were entered into multivariate models of the logistic regression by enter method in order to identify interaction between variables and to control for potential confounders. 
Table 2 Association of relapse with socio demographic characteristics (bivariate logistic regression)

\begin{tabular}{|c|c|c|c|c|c|c|}
\hline Variables & $\mathrm{N}$ & Relapse & No relapse & $P$-value & Crude OR & $95 \% \mathrm{Cl}$ \\
\hline \multicolumn{7}{|l|}{ Sex } \\
\hline Male & 279 & 71 (25.4 \%) & 208 (74.6 \%) & 0.54 & 1.18 & $0.50,2.00$ \\
\hline Female & 107 & 24 (22.4 \%) & 83 (77.6 \%) & & Reference & \\
\hline \multicolumn{7}{|l|}{ Age } \\
\hline $18-24$ & 79 & 14 (17.7 \%) & 65 (82.3\%) & 0.16 & 0.62 & $0.39,1.20$ \\
\hline $25-34$ & 186 & 48 (25.8 \%) & 138 (74.2 \%) & & Reference & \\
\hline $35-44$ & 82 & $23(28 \%)$ & 59 (72 \%) & 0.70 & 1.12 & $0.63,2.01$ \\
\hline $45-54$ & 28 & 9 (32.1\%) & 19 (67.9\%) & 0.48 & 1.36 & $0.58,3.21$ \\
\hline $55-68$ & 11 & 1 (9.1\%) & 10 (90.9 \%) & 0.24 & 0.29 & $0.04,2.31$ \\
\hline \multicolumn{7}{|l|}{ Ethnicity } \\
\hline Oromo & 239 & 55 (23 \%) & 184 (77 \%) & & Reference & \\
\hline Amhara & 66 & 20 (30.3 \%) & 46 (69.7\%) & 0.23 & 1.46 & $0.79,2.66$ \\
\hline Gurage & 19 & 4 (21.1\%) & 15 (78.9 \%) & 0.85 & 1.89 & $0.28,2.80$ \\
\hline Kaffa & 26 & $4(15.4 \%)$ & 22 (84.6\%) & 0.379 & 0.61 & $0.20,1.84$ \\
\hline Dawro & 20 & 7 (35 \%) & $13(65 \%)$ & 0.23 & 1.80 & $0.69,4.74$ \\
\hline Yem & 5 & 1 (20 \%) & $4(80 \%)$ & 0.87 & 0.84 & 0. $09,7.64$ \\
\hline Other* & 11 & $4(36.4 \%)$ & 7 (63.6\%) & 0.32 & 1.91 & $0.54,6.77$ \\
\hline \multicolumn{7}{|l|}{ Religion } \\
\hline Orthodox & 97 & 25 (25.8\%) & 72 (74.2 \%) & 0.79 & 1.08 & $0.63,1.86$ \\
\hline Muslim & 234 & 57 (24.4 \%) & 177 (75.6 \%) & & Reference & \\
\hline Other** & 55 & $13(23.6 \%)$ & 42 (76.4 \%) & 0.91 & 0.96 & $0.48,1.92$ \\
\hline \multicolumn{7}{|l|}{ Frequency of worship } \\
\hline Frequently & 170 & $35(20.6 \%)$ & $135(79.4 \%)$ & & Reference & \\
\hline Sometime & 196 & $51(26 \%)$ & $145(74 \%)$ & 0.22 & 1.36 & $0.83,2.21$ \\
\hline Never & 20 & $9(45 \%)$ & $11(55 \%)$ & 0.02 & 3.16 & $1.21,8.21$ \\
\hline \multicolumn{7}{|l|}{ Marital status } \\
\hline Single & 179 & $44(24.6 \%)$ & $135(75.4 \%)$ & 0.93 & 0.98 & $0.61,1.57$ \\
\hline Married & 188 & $47(25 \%)$ & $141(75 \%)$ & & Reference & \\
\hline Divorced & 11 & 1 (9.1\%) & 10 (90.9\%) & 0.26 & 0.30 & $0.04,2.41$ \\
\hline Separated/widowed & 8 & $3(37.5 \%)$ & $5(62.5 \%)$ & 0.43 & 1.80 & $0.41,7.82$ \\
\hline \multicolumn{7}{|l|}{ Educational status } \\
\hline Illiterate & 50 & $12(24 \%)$ & $38(76 \%)$ & 0.65 & 1.19 & $0.56,2.50$ \\
\hline Primary & 176 & $37(21 \%)$ & 139 (79 \%) & & Reference & \\
\hline Secondary & 96 & 19 (19.8\%) & 77 (80.2 \%) & 0.81 & 0.93 & $0.50,1.72$ \\
\hline tertiary & 64 & $27(42.2 \%)$ & 37 (57.8 \%) & 0.001 & 2.74 & $1.48,5.07$ \\
\hline \multicolumn{7}{|l|}{ Occupation } \\
\hline Unemployed & 112 & $25(22.3 \%)$ & 87 (77.7 \%) & & Reference & \\
\hline Government employee & 87 & 29 (33.3 \%) & 58 (66.7 \%) & 0.09 & 1.74 & $0.93,3.27$ \\
\hline Merchant & 26 & $4(15.4 \%)$ & 22 (84.6 \%) & 0.44 & 0.63 & $0.20,2.01$ \\
\hline Farmer & 97 & $23(23.7 \%)$ & 74 (76.3 \%) & 0.81 & 1.08 & $0.57,2.06$ \\
\hline Other*** & 64 & 14 (21.9 \%) & 50 (78.1\%) & 0.95 & 0.97 & $0.46,2.04$ \\
\hline \multicolumn{7}{|l|}{ Income } \\
\hline $167-541$ & 96 & 21 (21.9\%) & 75 (78.1 \%) & 0.73 & 1.12 & $0.58,2.17$ \\
\hline $542-1000$ & 120 & $24(20 \%)$ & $96(80 \%)$ & & Reference & \\
\hline
\end{tabular}


Table 2 Association of relapse with socio demographic characteristics (bivariate logistic regression) (Continued)

\begin{tabular}{llllllr}
\hline 1001-1888 & 75 & $26(34.7 \%)$ & $49(65.3 \%)$ & 0.02 & 2.12 & $1.11,4.08$ \\
$\begin{array}{l}\text { 1889-10000 } \\
\text { Living condition }\end{array}$ & 95 & $24(25.3 \%)$ & $71(74.7 \%)$ & 0.36 & & \\
Alone & 32 & $5(15.6 \%)$ & $27(84.4 \%)$ & & Reference & \\
With family & 339 & $88(26 \%)$ & $251(74 \%)$ & 0.20 & 0.53 & $0.20,1.41$ \\
With relative & 15 & $2(13.3 \%)$ & $13(86.7 \%)$ & 0.28 & 0.44 & $0.10,1.98$ \\
\hline
\end{tabular}

Other* includes Wolayita, Tigrie and Hadiya

Other*includes Protestant, Catholic and Jehovah witness

Other*** includes wood workers, daily laborers, house wives and students

Variables with $p$-value $<0.05$ in the multivariate analyses were considered significant predictors of relapse.

\section{Results}

\section{Paricipants characteristics}

A total of 386 participants were approached to participate in the study and all of them agreed to participante with the response rate of $100 \%$. Nearly $72.3 \%(n=279)$ of participants were males; $61.9 \%(n=239)$ were Oromo in ethnic origin. Of the total participants, nearly $61 \%(n=234)$ were Islamic religion followers followed by Orthodox Christians (25.1\%; $n=97)$. Out of the total participants of this study, $73.5 \%(n=280)$ were diagnosed as cases of schizophrenia. The mean age of the particpants was $31.49 \pm$ SD 9.36 years ranging from 18 to 68 and $48.2 \%(n=186)$ were between the ages of 25-34 years. Nearly, half of the the study participants (48.7\%; $n=188)$ were married. Amongst the total study participants, $29 \%(n=112)$ were unemployed. The mean monthly income of the study participants was $1446.13 \pm 1291.27$ Ethiopian Birr (1 USD $=20.91$ ETB) (see Table 1).

\section{Prevalence of relapse among patients with psychotic disorders}

Out of the total participants, $24.6 \%(n=95)$ had at least one relapse or reoccurrence of psychotic symptoms within the past 6 months; $14.8 \%(n=57)$ had only one relapse; $9.8 \%(n=38)$ had more than one relapse. Prevalence of relapse among male participants was $25.4 \%(n=71)$. Nearly one fourth $(25.8 \%, n=48)$ of patients with relapse were found among the patients in the age group of 25-34 years (see Table 2).
Nearly one-fourth of participants who were diagnosed as having schizophrenia ( $25 \% n=70)$, schizophreniform and schizoaffective disorders $(25.5 \%, n=13)$ had psychotic relapse (Table 3).

\section{Factors associated with relapse}

Out of the total particpants, only $7.7 \%(n=30)$ reported that they were non-compliant to their medication. Of these, $50 \%(n=15)$ had relapse. Some of the reasons reported by participants for becoming non-compliant to their medication were forgetting to take medications $(8 \%, n=30)$, feeling better $(11.7 \%, n=45)$ and worsening of the symptoms $(9.3 \%, n=36)$. Out of the total particpants, $75.4 \%(n=291)$ reported that, medication makes them feel tired (see Table 4). Abnormal involuntary movement scale (AIMS) was done for all participants and $41 \%(n=157)$ of the participants had scored above the mean $(2.99 \pm$ SD 4.26) score. Out of patients who experienced medication side effects, $29.3 \%(n=46)$ reported having had a relapse (see Table 4).

Additionally, nearly half, $49 \%(n=173)$ of the total participants were found to drink alcohol. Of this, $7 \%$ $(n=27)$ had alcohol use disorders. Among patients with alcohol use disorders, $40.7 \%(n=11)$ were identified as having a psychotic relapse. Out of this patients, $81.5 \%$ $(n=22)$ were diagnosed with schizophrenia (see Table 5$)$.

The prevalence of relapse among patients with low social support was $26.8 \%(n=70)$ (see Table 6$)$. Nearly $29 \%(n=61)$ and $27.7 \%(n=41)$ of participants who sought religious and traditional support before coming to the hospital had relapse respectively (see Table 6). Among patients having comordbid psychiatric illnesses, $30(33.7 \%)$ of them had psychotic relapse. In the

Table 3 Association of relapse with the type of psychotic diagnosis (bivariate logistic regression)

\begin{tabular}{|c|c|c|c|c|c|c|}
\hline Variables & $\mathrm{N}$ & Relapse & No relapse & $P$-value & Crude OR & $95 \% \mathrm{Cl}$ \\
\hline \multicolumn{7}{|l|}{ Diagnosis } \\
\hline Schizophrenia & 280 & $70(25 \%)$ & $210(75 \%)$ & 0.62 & 1.19 & $0.60,2.39$ \\
\hline Schizophreniform and schizoaffective & 51 & $13(25.5 \%)$ & $38(74.5 \%)$ & 0.66 & 1.23 & $0.50,3.01$ \\
\hline Brief psychotic & 55 & $12(21.8 \%)$ & 43 (78.2 \%) & & Reference & \\
\hline
\end{tabular}


Table 4 Association of psychotic relapse with medication related factors (bivariate logistic regression)

\begin{tabular}{|c|c|c|c|c|c|c|}
\hline Variables & $\mathrm{N}$ & Relapse & No relapse & $P$-value & Crude OR & $95 \% \mathrm{Cl}$ \\
\hline \multicolumn{7}{|l|}{$\overline{\text { MARS }^{a}}$} \\
\hline Compliant & 356 & $80(22.5 \%)$ & 276 (77.5 \%) & 0.001 & 0.29 & $0.14,0.62$ \\
\hline Non-compliant & 30 & $15(50 \%)$ & 15 (50 \%) & & Reference & \\
\hline \multicolumn{7}{|l|}{$\mathrm{AIMS}^{\mathrm{b}}$} \\
\hline Below mean & 229 & 49 (21.4\%) & 180 (78.6 \%) & & Reference & \\
\hline Above mean & 157 & 46 (29.3\%) & 111 (70.7 \%) & 0.08 & 1.52 & $0.96,2.43$ \\
\hline
\end{tabular}

${ }^{a} M A R S$ medication adherence rating scale

${ }^{\mathrm{b}}$ AIMS abnormal involuntary movment scale

bivariate analyses, having comorbid psychiatric illness was significantly associated with relapse (Table 7).

After adjusting for potential confounders using multivariate logistic regression anlaysis, living with family compared to living alone, being compliant to medication high score social support and seeking religious help were statistically associated with reduced odds of developing psychotic relapse. The odds of developing psychotic relapse among patients living with family was $72 \%$ lower than that of patients living alone $(\mathrm{aOR}=0.28,95 \% \mathrm{CI}=0.08$, 0.93). The odds of developing psychotic relapse among patients compliant to medication was $69 \%$ lower than that of patients who were not compliant to medications $(\mathrm{aOR}=0.31,95 \% \mathrm{CI}=0.12,0.80)$. The odds of developing psychotic relapse among patients having high score on social support score was $48 \%$ lower than that of patients who were compliant to medications $(\mathrm{aOR}=0.52$, $95 \% \mathrm{CI}=0.28,0.95)$. The odds of developing psychotic relapse among patients reporting to have sought religious support was $45 \%$ lower than that of patients who have not sought religious support $(\mathrm{aOR}=0.55,95 \% \mathrm{CI}=0.31$, 0.96) (see Table 8).

On the other hand, the odds of developing psychotic relapse among participants who have experienced medication side effects was 1.83 times higher when compared to those who have never experienced medication side effects $(\mathrm{aOR}=1.83,95 \% \mathrm{CI}=1.01,3.31)$ (see Table 8).

\section{Discussions}

In this study, about one-third of the study participants were identified to have relapse. This finding was in agreement with a Canadian study (35.7 \%) [37]. However, the finding is lower than study findings from a community cohort study conducted in Butajira Ethiopia, (54 \%) [38]. This difference could be due to the difference in the type of the study. While our study was hospital-based, the study conducted in Butajira was a community-based study. This finding may be expected because psychotic patients in the community might not have been on therapy provided in modern health intitutions. In addition, the relapse rate in or study was lower than the study conducted in Hong Kong (48.1\%) [39].

In the current study, lower relapse was associated with living with family member compared to living alone, seeking religious support, high score on social support, and compliance to medication. This was in agreement with the findings of the studies conducted in South Africa and Hong Kong $[39,40]$. The odds of having relapse among participants who live with family was $72 \%$ lower than that of patients who live alone. This could be due to the reason that, when patients live alone; they do not have anyone to encourage or remind them to take their medication properly and attend their follow-up regularly. This is in agreement with the study done in Spain, which indicated that cohabitation with other

Table 5 Association of relapse with substance related factors (bivariate logistic regression)

\begin{tabular}{|c|c|c|c|c|c|c|}
\hline Variables & $\mathrm{N}$ & Relapse & No relapse & $P$-value & Crude OR & $95 \% \mathrm{Cl}$ \\
\hline \multicolumn{7}{|l|}{$\mathrm{CAGE}^{a}$} \\
\hline No problem problem drinking & 359 & 84 (23.4 \%) & $275(76.6 \%)$ & & Reference & \\
\hline Problem drinking & 27 & 11 (40.7 \%) & $16(59.3 \%)$ & 0.05 & 2.25 & $1.01,5.04$ \\
\hline \multicolumn{7}{|l|}{$\mathrm{DAST}^{\mathrm{b}}$} \\
\hline No & 213 & $43(20.2 \%)$ & $170(79.8 \%)$ & & Reference & \\
\hline Low & 33 & $4(12.1 \%)$ & 29 (87.9\%) & 0.28 & 0.55 & $0.18,1.63$ \\
\hline Moderate & 114 & $36(31.6 \%)$ & $78(68.4 \%)$ & 0.02 & 1.83 & $1.09,3.06$ \\
\hline Substantial & 26 & 12 (46.2 \%) & $14(53.8 \%)$ & 0.004 & 3.39 & $1.46,7.85$ \\
\hline
\end{tabular}

${ }^{a}$ Cudown, annoyed, guilty and eye opener

${ }^{\mathrm{b}}$ Drug abuse screening test 
Table 6 Association of relapse with social support, DUP, help seeking (bivariate logistic regression)

\begin{tabular}{|c|c|c|c|c|c|c|}
\hline Variables & $\mathrm{N}$ & Relapse & No relapse & $P$-value & Crude OR & $95 \% \mathrm{Cl}$ \\
\hline \multicolumn{7}{|l|}{ Social support } \\
\hline Low score & 261 & $70(26.8 \%)$ & $191(73.2 \%)$ & & Reference & \\
\hline High score & 125 & $25(20 \%)$ & $100(80 \%)$ & 0.15 & 0.68 & $0.41,1.14$ \\
\hline \multicolumn{7}{|l|}{ DUP ${ }^{a}$} \\
\hline Below mean & 221 & $50(22.6 \%)$ & $171(77.4 \%)$ & & Reference & \\
\hline Above mean & 165 & $45(27.3 \%)$ & $120(72.7 \%)$ & 0.30 & 1.28 & $0.81,2.04$ \\
\hline \multicolumn{7}{|c|}{ Sought support from traditional sources } \\
\hline Yes & 148 & $41(27.7 \%)$ & $107(72.3 \%)$ & 0.27 & 1.31 & $0.82,2.09$ \\
\hline No & 238 & $54(22.7 \%)$ & $184(77.3 \%)$ & & Reference & \\
\hline \multicolumn{7}{|c|}{ Sought religious support } \\
\hline Yes & 210 & $61(29 \%)$ & 149 (71 \%) & & Reference & \\
\hline No & 176 & 34 (19.3 \%) & 142 (80.7 \%) & 0.03 & 0.59 & $0.36,0.94$ \\
\hline
\end{tabular}

people improves compliance to medication because relatives could serve as supervisors [41].

In this study, the odds of developing psychotic relapse among patients who were compliant to their medication was $69 \%$ lower when compared to the odds among non-compliant patients. This finding is in agreement with the studies conducted in Norway and USA [11, 42]. This underscores the importance of interventions that improve compliance to medication as part of the measures taken to reduce psychotic relapse. Further studies are needed to identify interventions that are effective and feasible in the context for improving compliance to medication.

In the current study the prevalence of relapse among patients with medication side effects was $29.3 \%(n=46)$. An Indian study reported a relapse rate of $37.5 \%$ among patients with medication side effects [43]. This difference could be due to difference in the instrument (AIMS vs. clinical interview). We used AIMS, while the Indian study used clinical interview. The instrument we used for assessing medication side effect (AIMS) assesses only extra pyramidal side effects, and hence, it might have underestimated the magnitude of medication side effects.

In the current study, the odds of developing relapse among patients who have experienced medication side

Table 7 Association of relapse with comorbidity among the patients (bivariate logistic regression)

\begin{tabular}{|c|c|c|c|c|c|c|}
\hline Variables & $\mathrm{N}$ & Relapse & No relapse & $P$-value & Crude OR & $95 \% \mathrm{Cl}$ \\
\hline \multicolumn{7}{|c|}{ Comorbid psychiatric illness } \\
\hline Yes & 89 & 30 (33.7 \%) & $59(66.3 \%)$ & 0.02 & 1.82 & $1.08,3.05$ \\
\hline No & 297 & 65 (21.9\%) & $232(78.1 \%)$ & & Reference & \\
\hline \multicolumn{7}{|c|}{ Comorbid medical illness } \\
\hline Yes & 24 & $9(37.5 \%)$ & $15(62.5 \%)$ & 0.14 & 1.93 & $0.81,4.56$ \\
\hline No & 362 & $86(23.8 \%)$ & $276(76.2 \%)$ & & Reference & \\
\hline
\end{tabular}

effects was 1.83 times higher when compared to that of patients who have never experienced medication side effects. This underscores the importance of emphasizing detection and treatment of medication side effects among psychotic patients. The use of antipsychotic drugs that are asssociated with less side effects may be considered. A meta-analysis has shown that risperidone use was associated with less side effects compared to haloperidol [44]. In addition, it is essential to link mentally ill persons to NGOs (non-governmental oraganizations) that support recovery and rehablitation of persons with mental disorders. Moreover, developing and strengthening culturally acceptable community rehabilitation intervention and recovery-oriented services that help to develop the skills of patients in dealing with mental health problem is essential. Components such as psycho-education, family intervention, relapse prevention, adherence support, stress and anger management should be included in community based rehabilitation interventions [45].

In the current study, the odds of having relapse among patients who had sought religious support before coming to the hospital was $45 \%$ lower than that of patients who have never sought religious support. This could be because some religious practices help patients to cope with the illness and avoid the use of psychoactive substances [46]. The odds of having psychotic relapse among patients who had high social support score was $48 \%$ lower than that of patients who had low social support score. This finding is in agreement with one meta-analysis, which showed that good social support was associated with less relapse $[47,48]$. This indicates the importance of focusing on patients living alone, who have low or no social support. Also, it is essential to arrange referral mechanism for psycho social support services. The psychiatry clinic also needs to employ regular program of psycho education and counseling. In addition, providing 
Table 8 Predictors of relapse among patients with psychotic disorders (multivariate logistic regression)

Variables $\quad P$-value Adjusted OR $\frac{95 \% \mathrm{Cl}}{\text { Lower Upper }}$

\begin{tabular}{|c|c|c|c|c|}
\hline & & & Lower & Upper \\
\hline \multicolumn{5}{|l|}{$\overline{S e x}$} \\
\hline Male & 0.75 & 0.89 & 0.45 & 1.76 \\
\hline Female & & Reference & & \\
\hline Age & & & & \\
\hline
\end{tabular}

$$
\begin{aligned}
& 18-24 \\
& 25-34 \\
& 35-44 \\
& 45-54 \\
& 55-68
\end{aligned}
$$$$
45-54
$$$$
\text { Ethnicity }
$$$$
\text { Oromo }
$$$$
\text { Amhara }
$$$$
\text { Gurage }
$$$$
\text { Kaffa }
$$$$
\text { Dawro }
$$$$
\text { Yem }
$$

Other*

Frequency of worship

Frequently

Sometime

Never

Educational status

Illiterate

Secondary

Tertiary

Occupation

Unemployed

Government employee

Merchant

Farmer

Other***

Income

$$
\begin{aligned}
& 167-541 \\
& 542-1000
\end{aligned}
$$

1001-1888

1889-10000

Living condition

Alone

With family

With relative$$
0.13-0.53
$$

$\begin{array}{llll}0.13 & 0.53 & 0.24 & 1.20 \\ & \text { Reference } & & \\ 0.57 & 1.22 & 0.62 & 2.42 \\ 0.45 & 1.49 & 0.53 & 4.14 \\ 0.25 & 0.26 & 0.03 & 2.63\end{array}$

$\begin{array}{ll}0.25 & 0.26\end{array}$

Reference

0.81

0.43

0.08

0.33

0.76

0.66

1.10

0.58

0.31

1.87

0.67

0.65

Reference

0.18

0.05

1.51

3.64

0.52

1.34

Reference

0.99

0.99

0.01

3.49

Reference

0.99

0.99

0.3

0.73

0.79

1.25

1.26

0.43

1.35

Reference

0.10

1.10

0.87

1.07

Reference

0.04

\begin{tabular}{|c|c|c|c|c|}
\hline \multicolumn{5}{|l|}{$\overline{\text { MARS }^{a}}$} \\
\hline Compliant & 0.02 & 0.31 & 0.12 & 0.80 \\
\hline Non-compliant & & Reference & & \\
\hline \multicolumn{5}{|l|}{ AIMS $^{\mathrm{b}}$} \\
\hline Below mean & & Reference & & \\
\hline Above mean & 0.04 & 1.83 & 1.01 & 3.31 \\
\hline \multicolumn{5}{|l|}{$\mathrm{CAGE}^{\mathrm{C}}$} \\
\hline No problem of dri & & Reference & & \\
\hline Drinking Problem & 0.95 & 1.04 & 0.32 & 3.34 \\
\hline \multicolumn{5}{|l|}{$\mathrm{DAST}^{\mathrm{d}}$} \\
\hline No & & Reference & & \\
\hline Low & 0.48 & 0.64 & 0.19 & 2.19 \\
\hline Moderate & 0.16 & 1.68 & 0.82 & 3.45 \\
\hline Substantial & 0.11 & 2.61 & 0.810 & 8.42 \\
\hline \multicolumn{5}{|l|}{ Social support } \\
\hline Low score & & Reference & & \\
\hline High score & 0.04 & 0.52 & 0.28 & 0.95 \\
\hline \multicolumn{5}{|l|}{ Religious help seeking } \\
\hline Yes & & Reference & & \\
\hline No & 0.04 & 0.55 & 0.31 & 0.96 \\
\hline \multicolumn{5}{|c|}{ Comorbid psychiatric illness } \\
\hline Yes & 0.52 & 0.77 & 0.35 & 1.70 \\
\hline No & & Reference & & \\
\hline \multicolumn{5}{|c|}{ Comorbid medical illness } \\
\hline Yes & 0.22 & 1.98 & 0.67 & 5.90 \\
\hline No & & Reference & & \\
\hline
\end{tabular}

0.28

0.23
0.32
Table 8 Predictors of relapse among patients with psychotic disorders (multivariate logistic regression) (Continued)

${ }^{\mathrm{a}}$ MARS: medication adherence rating scale

${ }^{\mathrm{b}}$ AIMS abnormal involuntary movment scale

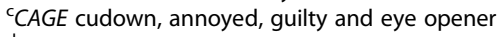

${ }^{\mathrm{d}}$ DAST drug abuse screening test

Other* includes Wolayita, Tigrie and Hadiya

Other*** includes wood workers, daily laborers, house wives and students

support for mentally ill people at the community level is essential. Furthermore, Jimma town health office may consider building rehabilitation centers or providing psycho social support for people who have no social support. The health office also needs collaboration with Jimma town education office to create educational opportunities for mentally ill individuals. To provide support for mentally ill people at the community level, integrating mental health services into urban and rural health extension services may be helpful.

Even though not statistically significant, $40.7 \%(n=11)$ of patients with problem drinking had psychotic relapse. In addition, $31.6 \%(n=36)$ of patients with moderate level of khat abuse had relapse. This could be because of the fact that patients use psychoactive substances to get relief from the symptoms of the illness and side effects. A study 
conducted in Ethiopia at Ammanuel Hospital on patients with schizophrenia showed that alcohol and khat abuse were contributing factors for relapse of psychotic symptoms and re-hospitalization [15]. Another literature review on substance mis-use and mental illness showed that alcohol use even with small amount was associated with increase symptomatology and rehospitalization [13]. A study conducted in Australia showed that substance mis-use was significantly associated with relapse of positive symptoms [14].

Comorbidity of medical illnesses in this study on patients who had relapse was $37.5 \%(n=9)$. The study conducted in South Africa on patients with schizophrenia showed that $45.5 \%(n=6)$ of patients had comorbid medical illnesses [40].

Nearly $27.3 \%(n=45)$ of participants who had long duration before treatment had relapse of psychotic illness. In this study, duration of untreated psychoses (DUP) was not significantly associated with relapse. Study conducted in USA found that there is positive correlation between DUP and number of relapses [18].

In this study nearly one-forth $(n=70)$ of respondents with diagnosis of schizophrenia had relapse. This could be due to the nature of the illness. Study conducted in Hong Kong on first episode psychosis showed that the diagnosis schizophrenia was associated with increased risk of relapse [39].

Our current study has used standard scales and instruments such as MARS, AIMS, DAST-10, CAGE and SSQ6. The findings have implications for health program design and service improvement especially for the country and context. Our study has some limitations. First, the instrument we used for assessing medication side effects (AIMS) assesses only extra pyramidal side effects. This might have underestimated the rate of medication side effects faced by participants. Secondly, the study design is cross sectional in nature; hence, it was difficult to identify the cause and effect relationship between study variables.

\section{Conclusions}

In this study, about one-third of the respondents had relapse. Living with family, seeking religious support, high social support score and compliance with medication were independently associated with reduced odds of developing psychotic relapse. Experiencing medication side effects was associated with increased odds of developing psychotic relapse. Clinicians need to detect and manage medication side effects faced by the patients. Intervening noncompliance to medication may help in preventing psychotic relapse that may result because of noncompliance. The linkage of patients to social and religious supports may help the patients in improving compliance to medication and reducing psychotic relapse. Moreover, developing and strenghtneing community based rehabilitation services with components such as psycho education, family intervention, relapse prevention, adherence support and stress and anger management, is needed. Further studies are needed to identify effective and feasible interventions that address compliance to medication.

\section{Acknowledgements}

We would like to thank Jimma University for funding the project. We also appreciate participants for their time.

\section{Funding}

The study was entirely funded by Jimma University College of Health Sciences throughout inception, data collection and analysis.

\section{Availability of data and materials}

All the data included in the manuscript has been included in the form of tables. The de-identified raw data is not publicly available. But the de-identifyied raw data can be requested from the corresponding author after providing the necessary justification for request.

\section{Authors' contributions}

MF, MS and GTF participated in the design, conduct, data analyses, report writing and manuscript preparation. All authors read and approved the final manuscript.

\section{Competing interests}

The authors declare that they have no competing interests.

Consent for publication

Not applicable.

Ethics approval and consent to participate

Ethical clearance was obtained from the ethical review committee of Jimma University, College of Public Health and Medical Sciences. Written informed consent was obtained from each participant before participation. Information obtained in due course was kept confidentially.

\section{Author details}

${ }^{1}$ Amanuel Mental Health Specialized Hospital, Addis Ababa, Ethiopia. ${ }^{2}$ Department of Psychiatry, Jimma University, Jimma, Ethiopia. ${ }^{3}$ Department of Health Education and Behavioral Science, Jimma University, Jimma, Ethiopia. ${ }^{4}$ The Joanna Briggs Institute, University of Adelaide, Adelaide, Australia.

Received: 17 December 2015 Accepted: 17 October 2016 Published online: 20 October 2016

\section{References}

1. Kessler RC, Aguilar-Gaxiola S, Alonso J, Chatterji S, Lee S, Ormel J, Üstün TB, Wang PS. The global burden of mental disorders: an update from the WHO world mental health (WMH) surveys. Epidemiologia e psichiatria sociale. 2009;18(01):23-33.

2. Shibre T, Kebede D, Alem A, Negash A, Deyassa N, Fekadu A, Fekadu D, Jacobsson L, Kullgren G. Schizophrenia: illness impact on family members in a traditional society-rural Ethiopia. Soc Psychiatry Psychiatr Epidemiol. 2003;38(1):27-34.

3. Rössler W, Salize HJ, Os JV, Riecher A. Size of burden of schizophrenia and psychotic disorders. European Neuro-psychopharmaco. 2005;15:399-409.

4. Davies T. Psycho social factors and relapse of schizophrenia. Br Med J. 1994; 309(6951):353

5. Almond S, Knapp M, Francois C, Toumi M, Brugha T. Relapse in schizophrenia: costs, clinical outcomes and quality of life. Br J Psychiatry. 2004;184:346-51.

6. Capdevielle D, Boulenger JP, Villebrun D, Ritchie K. Schizophrenia patients' length of stay: mental health care implication and medico-economic consequesnses. Encéphale. 2009;35(4):394-9.

7. Weiden PJ, Olfson M. Cost of relapse in schizophrenia. Schizophr Bull. 1995; 21(3):419-29. 
8. Csernansky JG, Mahmoud R, Brenner R. A comparison of risperidone and haloperidol for prevention of relapse in patients with schizophrenia. N Engl J Med. 2002;346(1):16-22.

9. Munro J, Osborne S, Dearden L, Pascoe K, Gauthier A, Price M. Hospital treatment and management in relapse of schizophrenia in the UK: associated costs. Psychiatrist. 2011;35:95-100.

10. Moncrieff J. Does antipsychotic withdrawal provoke psychosis? Review of the literature on rapid onset psychosis (super sensitivity psychosis) and withdrawal related relapse. Acta Psychiatr Scand. 2006;114(1):3-13.

11. Morken G, Widen JH, Grawe RW. Non-adherence to antipsychotic medication relapse and rehospitalization in recent-onset schizophrenia. BMC Psychiatry. 2008;8:32.

12. Gregg L, Barrowclough C, Haddock G. Reasons for increased substance use in psychosis. Sci Direct Clin Psychol Rev. 2007;27(4):494-510.

13. Drake RE, Mercer-McFadden C, Mueser KT, McHugo GJ, Bond GR. Review of integrated mental health and substance abuse treatment for patients with dual disorders. Schizophr Bull. 1998;24(4):589-608.

14. Wade D, Harrigon S, Edwards J, Burgess PM, Whelam G, McGorry PD. Substance mis-use in first episode psychosis: 15 month prospective follow up study. $\mathrm{Br}$ J Psychiatry. 2006;189:229-34.

15. Bimerew MS, Sonn FC, Kortenbout WP. Substance abuse and the risk of readmission of people with schizophrenia at Amanuel psychiatric hospital. Ethiopia Curationis. 2007;30(2):74-81.

16. Owens DC, Johnstone EC, Miller P, Macmillan JF, Crow TJ. Duration of untreated illness and outcome in schizophrenia: test of predictions in relation to relapse risk. Br J Psychiatry. 2010;196(4):296-301.

17. Altamura MS, Bassetti R, Sassella F, Salvadori D, Mundo E. Duration of untreated psychosis as a predictor of outcome in first-episode schizophrenia: a retrospective study. Schizophr Res. 2001;52(1-2):29-36.

18. Cechnicki A, Hanuszkiewicz I, Polczyk R, Bielańska A. Prognostic value of duration of untreated psychosis in long-term outcome of schizophrenia. Med Sci Monit. 2011;17(5):CR277-83.

19. Kozumplik O, Uzun S, Jakovljević M. Psychotic disorders and comorbidity: somatic illness vs. side effect. Psychiatr Danub. 2009;21(3):361-7.

20. Dernovšek MZ, Šprah L. Comorbid anxiety in patients with psychosis. Psychiatr Danub. 2009;21(1):43-50.

21. Buckley PF, Miller BJ, Lehrer D, Castle DJ. Psychiatric comorbidities and Schizophrenia. Schizophr Bull. 2009;35(2):383-402.

22. Zergaw AG. Economic burden of schizophrenia and bipolar disorders in Ethiopia. Doctoral dissertation, Addis Ababa University. 2008; 51-52.

23. Historical background of Jimma University College of public health. Available at https://www.ju.edu.et/jush/. Accessed 14 May 2014.

24. Stahl SM. Essential psychopharmacology. 2nd ed. Sandiego: Cambridge University press; 2000.

25. Thompson K, Kulkarni L, Sergejew A. Reliability \& validity of a new medication adherence rating scale for the psychoses. Schizophr Res. 2000;42(3):241-7.

26. Hardeman MS, Richard K, Narisimhan M. Simplifying adherence in schizophrenia. Psychiatr Serv. 2010;61(4):405-8.

27. Sadock BJ. Kaplan \& Sadock's comprehensive textbook of psychiatry. Philadelphia: lippincott Williams \& wilkins; 2000.

28. Tonelli $H$, Tonelli $D$, Poiani GR, Vital MA, Andreatini R. Reliability and clinical utility of a Portuguese version of the abnormal involuntary movements scale (AIMS) for tardive dyskinesia in Brazilian patients. Braz J Med Biol Res. 2003;36(4):511-4.

29. Dhalla S, Kopec JA. The CAGE questionnaire for alcohol misuse: a review of reliability and validity studies. Clin Invest Med. 2007;30(1):33-41.

30. Yudko E, Lozhkina O, Fouts A. A comprehensive review of the psychometric properties of the drug abuse screening test. J Subst Abus Treat. 2007;32(2): 189-98.

31. Zenebe Y, Feyissa GT, Krahl W. Khat use in persons with mental illness in Southwest Ethiopia: a cross-sectional study. J Addict Res Ther. 2015;6(242):2.

32. Soboka M, Tesfaye M, Feyissa GT, Hanlon C. Khat use in people living with HIV: a facility-based cross-sectional survey from South West Ethiopia. BMC psychiatry. 2015;15(1):1

33. Cocco KM, Carey KB. Psychometric properties of the drug abuse screening test in psychiatric outpatients. Psychol Assess. 1998;10:408-14.

34. French MT, Roebuck MC, McGeary KA, Chitwood KA. Using the drug abuse screening test (DAST-10) to analyze health services utilization and cost for substance users in a community-based setting. Subst Use Misuse. 2001;36:927-46.

35. Maisto SA, Carey MP, Carey KB, Gordon CM, Gleason JR. Use of the AUDIT and the DAST-10 to identify alcohol and drug use disorders among adults with a severe and persistent mental illness. Psychol Assess. 2000;12:186-92.
36. Sarason IG, Sarason BR, Shearin EN, Plerce RG. A brief measure of social support: practical and theoretical implication. J Soc Pers Relat. 1987:4:497-510.

37. Addington $D$, Patten $S$. Relapse rates in an early psychosis treatment service. Acta Psychiatr Scand. 2007;115(2):126-31.

38. Alem A, Kebede D, Fekadu A, Shibre T, Fekadu D, Beyero T, et al. Clinical course and outcome of schizophrenia in a predominantly treatment-naive cohort in rural Ethiopia. Schizophr Bull. 2009;35(3):646-54.

39. Hui C, Tang J, Leung C, Wong HY, Chang C, Chan KW, et al. A three year retrospective cohort study of predictors of relapse in first episode psychosis. Aust N Z J Psychiatry. 2013;47(8):746-53.

40. Kazadi NJ, Moosa MY, Jeenah FY. Factors associated with relapse in schizophrenia. S Afr J Psychol. 2008;14(2):52-62.

41. de la Vega DC, Álvarez T, Meyer JA, de la Serna I. P01-522-Non compliace of treatment depending on diagnosis and family containment. European Psychiatry. 2011;26:526

42. Robinson D, Woerner MG, Alvir JM, Bilder R, Goldman R, Geisler S, et al. Predictors of relapse following response from a first episode of schizophrenia or schizoaffective disorder. Arch Gen Psychiatry. 1999;56(3):241-7.

43. Chabungbam G, Avasthi A, Sharan P. Sociodemographic and clinical factors with relapse in schizophrenia. Psychiatry Clin Neurosci. 2007;61(6):587-93.

44. Csernansky JG, Mahmoud R, Brenner R. A comparison of risperidone and haloperidol for the prevention of relapse in patients with schizophrenia. $\mathrm{N}$ Engl J Med. 2002;346(1):16-22.

45. Asher L, Fekadu A, Hanlon C, Mideksa G, Eaton J, Patel V, De Silva MJ. Development of a community-based rehabilitation intervention for people with schizophrenia in Ethiopia. PLoS One. 2015;10(11):e0143572.

46. Huguelet $P$, Koenig HG. Religion and spirituality in psychiatry. Cambridge University Press; 2009

47. Alvarez M, Priede A, Hetrick SE, Bendall S, Killackey E, Parker AG, et al. Risk factors for relapse following treatment for first episode psychosis: a systematic review and meta analysis of longitudinal studies. Schizophr Res. 2012;139(1-3):116-28.

48. Halford WK, Steindl S, Varghese FN, Robert S. Observed family interaction and outcome in patients with first-admission psychoses. Behav Ther. 1999;30:555.

\section{Submit your next manuscript to BioMed Central and we will help you at every step:}

- We accept pre-submission inquiries

- Our selector tool helps you to find the most relevant journal

- We provide round the clock customer support

- Convenient online submission

- Thorough peer review

- Inclusion in PubMed and all major indexing services

- Maximum visibility for your research

Submit your manuscript at www.biomedcentral.com/submit
Biomed Central 